\title{
MECHANICAL PROPERTIES OF LOW-TEMPERATURE BAINITE
}

\author{
C. Garcia-Mateo ${ }^{1, \mathrm{a}}$, F.G. Caballero ${ }^{1, \mathrm{~b}}$ and H.K.D.H Bhadeshia ${ }^{2, \mathrm{c}}$ \\ ${ }^{1}$ Department of Physical Metallurgy, Centro Nacional de Investigaciones Metalúrgicas \\ (CENIM-CSIC), Avda. Gregorio del Amo, 8, 28040, Madrid, Spain. \\ ${ }^{2}$ University of Cambridge, Department of Materials Science and Metallurgy, Pembroke Street, \\ Cambridge CB2 3QZ, UK. \\ ${ }^{\mathrm{a}}$ cgm@cenim.csic.es, ${ }^{\mathrm{b}}$ fgc@,cenim.csic.es, ${ }^{\mathrm{c}} \underline{\mathrm{hkdb} @ \text { cus.cam.ac.uk }}$
}

Keywords: Low temperature bainite, mechanical properties, plate thickness, dislocation density

\begin{abstract}
The mechanical properties of a bainitic microstructure with slender ferrite plates $(20-65 \mathrm{~nm}$ in thickness) in a matrix of carbon-enriched retained austenite have been characterized. The microstructure is generated by isothermal transformation at temperatures in the range $200-300^{\circ} \mathrm{C}$. A yield strength as high as $1.5 \mathrm{GPa}$ and an ultimate tensile strength between 1.77 to $2.2 \mathrm{GPa}$ has been achieved, depending on the transformation temperature. Furthermore, the high strength is frequently accompanied by ductility $(\leq 30 \%)$ and respectable levels of fracture toughness $\left(<45 \mathrm{MPa} \mathrm{m}{ }^{0.5}\right)$. This unusual combination of properties is attributed to the exceptionally fine scale of the carbidefree bainitic microstructure and the associated retained austenite.
\end{abstract}

\section{Introduction}

A new generation of bainitic steels has recently been developed using detailed phase transformation theory for the bainite reaction [1]. The calculations rely on the fact that nucleation occurs under paraequilibrium conditions and that the nucleus evolves into a plate by diffusionless growth. The steels have a simple metallurgy which can be summarized as follows [2-4]:

- low bainitic and martensitic transformation temperatures ( $B_{S}$ and $M_{S}$ respectively) both to maximize the fraction of bainite and to reduce the scale of the microstructure;

- the precipitation of cementite is avoided by alloying with silicon; cementite is a brittle phase in high strength steels;

- in spite of the low transformation temperatures, the steel is designed to achieve the required bainitic microstructure in realistic time-scales during isothermal transformation. Furthermore, the hardenability is engineered so that phases such as allotriomorphic ferrite and pearlite are avoided during cooling from the austenitisation temperature.

In this work we present a detailed study of the relationship between microstructure and mechanical properties for a selected variant of the new alloy system.

\section{Material and experimental procedure}

The chemical composition of the alloy is listed in Table 1 . Samples $10 \times 4 \times 4 \mathrm{~cm}$ were homogenized at $1200^{\circ} \mathrm{C}$ in a vacuum furnace for two days, followed by slow cooling to ambient temperature, achieved by switching off the furnace in order to obtain a pearlitic microstructure. This 
is important in order to avoid martensite which because of the high carbon concentration is brittle. Any martensite plates which crack can permanently compromise the integrity of the sample. A vacuum furnace was also used to protect samples against oxidation during austenitisation at $900^{\circ} \mathrm{C}$ for $30 \mathrm{~min}$ prior to isothermal heat treatment, at 200,250 and $300^{\circ} \mathrm{C}$ respectively. The alloy contains manganese and chromium for hardenability, and silicon to prevent cementite precipitation [1], so that the carbon that is partitioned into the residual austenite remains there to be retained down to ambient temperature. Molybdenum is added to prevent temper embrittlement due to phosphorous. The carbon concentration was selected to suppress $\mathrm{B}_{\mathrm{S}}$ whilst at the same time allowing realistic transformation times. Cobalt is added to accelerate the rate of reaction by increasing the free energy difference between the ferrite and austenite phases. Detailed information on the metallurgical design of the alloys and of the heat treatment is given in [4].

Table 1. Chemical composition in wt.\%, and measured bainite and martensite transformation temperatures.

\begin{tabular}{|cccccccc|cc|}
\hline $\mathrm{C}$ & $\mathrm{Si}$ & $\mathrm{Mn}$ & $\mathrm{Mo}$ & $\mathrm{Cr}$ & $\mathrm{Co}$ & $\mathrm{P}$ & $\mathrm{S}$ & $\mathrm{M}_{\mathrm{S}} /{ }^{\circ} \mathrm{C}$ & $\mathrm{B}_{\mathrm{S}} /{ }^{\circ} \mathrm{C}$ \\
\hline 0.80 & 1.59 & 2.01 & 0.24 & 1 & 1.51 & 0.002 & 0.002 & 120 & 360 \\
\hline
\end{tabular}

X-ray experiments were conducted using a Phillips PPW1730 diffractometer at a scan rate (29, where $\theta$ is the Bragg angle) of $0.1^{\circ} \mathrm{min}^{-1}$ over the range $2 \theta=30-110^{\circ}$, with unfiltered $\mathrm{Cu} \mathrm{K}_{\alpha}$ radiation. The system was operated at $45 \mathrm{kV}$ and $45 \mathrm{~mA}$. The peak positions and widths of Bragg reflections were determined by a self-consistent profile-fitting technique using the Pearson VII function. The fraction of retained austenite was calculated using the integrated intensities of 111, 200, 220 and 311 austenite and 110,002, 112 and 022 peaks of ferrite. This helps avoid bias due to crystallographic texture [5]. The ferrite carbon content was calculated using of the relationship between its lattice parameter and chemical composition as reported in [6]. The X-ray data from the microstructure were also analysed for non-uniform strains. Diffraction peaks are broadened by the presence of non-uniform strains that systematically shift atoms from their ideal positions, and by the finite size of coherently diffracting domains. These two effects have a different dependence on the value of $\theta$ [7]. The non-uniform strain effect can therefore be separated, since the slope of a plot of $\beta_{h k l} \cos \left\{\theta_{h k l}\right\}$ versus $4 \sin \left\{\theta_{h k l}\right\}$ is equal to a measure of the non-uniform strain $\varepsilon$ [7]. The parameter $\beta$ is the measured peak broadening. The dislocation density, $\rho$, is calculated as follows [8]:

$$
\rho=\frac{6 \pi \varepsilon^{2}}{b^{2}}
$$

where $b$ stands for the Burgers vector of dislocations in $\alpha$-Fe.

Specimens for transmission electron microscopy were machined from $3 \mathrm{~mm}$ diameter rods which were sliced into $100 \mu \mathrm{m}$ discs. These were ground down to $50 \mu \mathrm{m}$ thickness using 1200 grit silicon carbide paper, for electropolishing at $50 \mathrm{~V}$ using a twin jet unit. The electrolyte consisted of 5\% perchloric acid, 15\% glycerol and 80\% methanol. A JEOL JEM-200CX transmission electron microscope operated at $200 \mathrm{kV}$ was used to examine the thin foils. From where it was determine the ferrite true plate thicknesses $t$, by measuring the mean lineal intercept $\bar{L}=\pi t / 2$ in a direction normal to the plate length.

Tensile specimens with a section of $5 \mathrm{~mm}$ diameter and a gauge length of $25 \mathrm{~mm}$ were tested at room temperature using an Instron-8032 fitted with a $100 \mathrm{kN}$ load cell. A crosshead speed of 0.1 $\mathrm{mm} / \mathrm{min}$ was used in all the experiments. Plane strain fracture toughness $\left(\mathrm{K}_{\mathrm{IC}}\right)$ was obtained on compact tension specimens of $B=13 \mathrm{~mm}, W=26 \mathrm{~mm}$ and $a / W=0.5$ tested at room temperature in a servo-hydraulic machine. Where $B$ and $W$ stands for the test piece thickness and width respectively, and $a$ for the effective crack length. The development of the fatigue crack and its 
propagation by applying an increasing force was done according to the British standard BS 5447 . All mechanical experiments were assisted by electronic equipment that allowed the continuous tracking of load-displacement data during the tests. All samples were machined from the softened (pearlitic) state after homogenization and subsequently heat-treated to the desired conditions.

\section{Results and discussion}

The general microstructure consists of plates of bainitic-ferrite and retained austenite, as described in previous work and illustrated in Fig. 1, [2,3]. This figure summarizes experimental data concerning the microstructure as a function of transformation temperature; the transformation time was in all cases sufficient to ensure the cessation of the bainite reaction. The bainitic ferrite fraction, its carbon content and dislocation density increases as the transformation temperature is reduced $[1,9]$. There are two distinctive features of bainite generated by transformation at low temperatures. The first is the small thickness of the ferrite plates, about $30 \mathrm{~nm}$ and $65 \mathrm{~nm}$ in the microstructures obtained at $200^{\circ} \mathrm{C}$ and $300^{\circ} \mathrm{C}$ respectively. This is a consequence of the increased strength of austenite at low temperatures and the magnitude of the free energy change accompanying transformation [10]. The second is the large amount of carbon, up to $0.30 \mathrm{wt} . \%$, which remains trapped inside the bainitic ferrite.
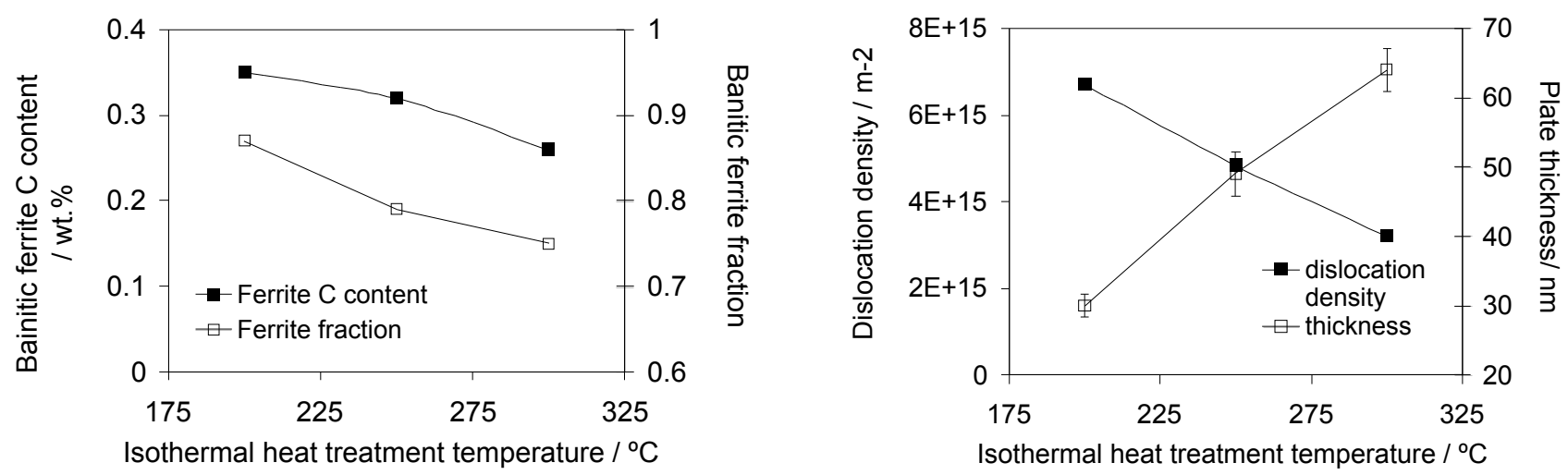

Fig. 1. Summary of quantitative experimental data. Fraction of bainitic ferrite (the remainder being retained austenite) obtained after isothermal transformation at different temperatures and times, ensuring that bainitic transformation was finished. The thickness refers to $t$, the stereologicaly corrected value [11].

Fig. 2 presents the transformation-temperature dependence of engineering stress versus strain curves. Deformation at room temperature is characterized by continuous yielding, as might be expected from mixed microstructures containing dislocations introduced by the plastic accommodation of the shape change due to transformation. As evident in Fig. 2, plastic deformation is uniformly distributed along the gauge length of the tensile specimens, showing little or no necking. Almost all the permanent deformation is uniform strain. 


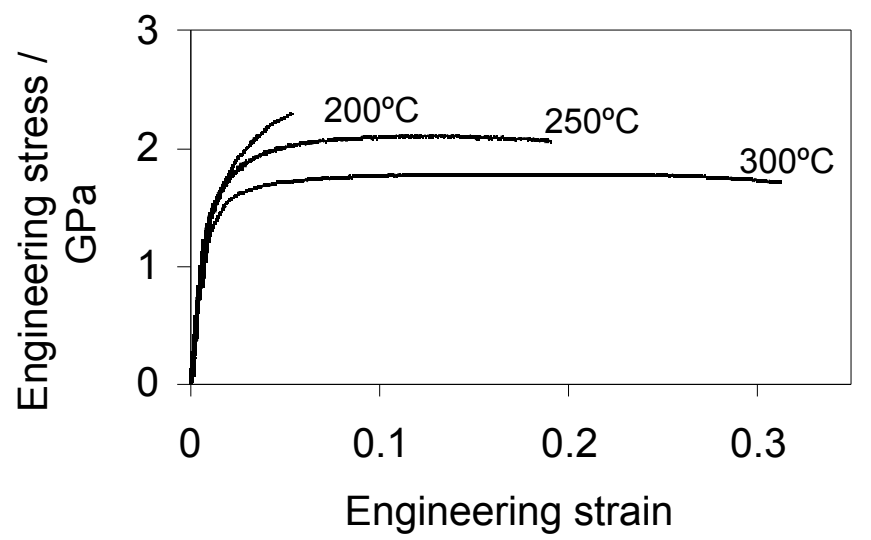

Fig. 2. Stress-strain curves for room temperature tensile tests. The bainite transformation temperatures are indicated.

The material exhibits an extraordinary combination of properties, with a yield strength (YS) greater than $1.2 \mathrm{GPa}$, and an ultimate tensile strength (UTS) ranging from 1.77 to $2.2 \mathrm{GPa}$, the latter in the case of the $200^{\circ} \mathrm{C}$ microstructure (Fig. 3). Such a combination of properties has never before been achieved in bainitic steels. Fracture toughness $\left(\mathrm{K}_{\mathrm{IC}}\right)$ and ductility both decrease as the strength increases. The microstructure obtained by transformation at $300^{\circ} \mathrm{C}$ exhibits $\sim 30 \%$ elongation and fracture toughness of $44 \mathrm{MPa} \mathrm{m} \mathrm{m}^{0.5}$, very high values if compared with those obtained by transformation at $200^{\circ} \mathrm{C}$, where elongation is reduced $\sim 20 \%$ and toughness by half.
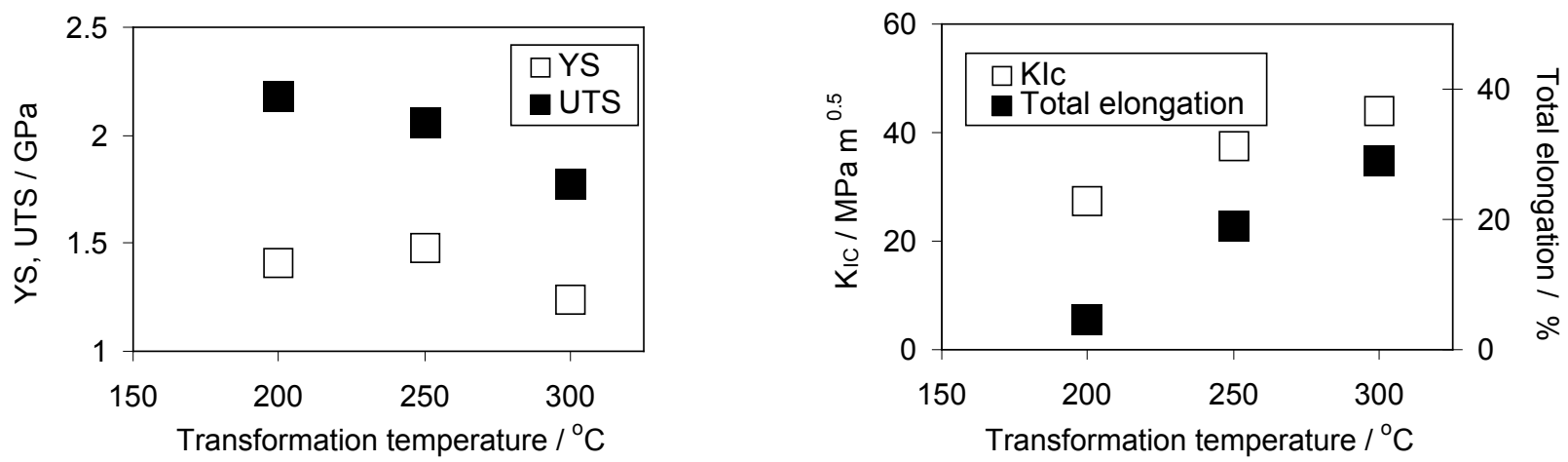

Fig. 3. Transformation temperature dependences of UTS, YS, total elongation and $\mathrm{K}_{\mathrm{IC}}$ (fracture toughness).

The increase in strength in microstructures generated at lower temperatures is due to the thinner bainitic ferrite plates, Fig. 1. Theory indicates that the contribution to strength due to the size of the plates is given by $\ddot{A} o ́ \cong 115(\bar{L})^{-1}$ in $\mathrm{MPa}[12-14]$, where $\bar{L} \cong 2 t$ is the mean linear intercept in micrometers. It is easily shown that much of the strength of low-temperature bainite is due to the extremely fine plates of ferrite. For example, for plates thickness of $30 \mathrm{~nm} \Delta \sigma \cong 1916 \mathrm{MPa}$, whereas $\Delta \sigma \cong 898 \mathrm{MPa}$ for a plate thickness of $64 \mathrm{~nm}$ at transformation temperature of $300^{\circ} \mathrm{C}$. It is therefore expected that the strength varies linearly with the reciprocal of the ferrite plate thickness even when other contributions are neglected. In practice, the mean linear intercept $\bar{L}$ should depend on the fraction of bainite, $V_{b}$. If plates are assumed to be square, then $(\bar{L})^{-1} \propto V_{b} / t$ [4]. It follows that the UTS and YS can be related to the ratio $V_{b} / t$, as shown in Fig. 4. 


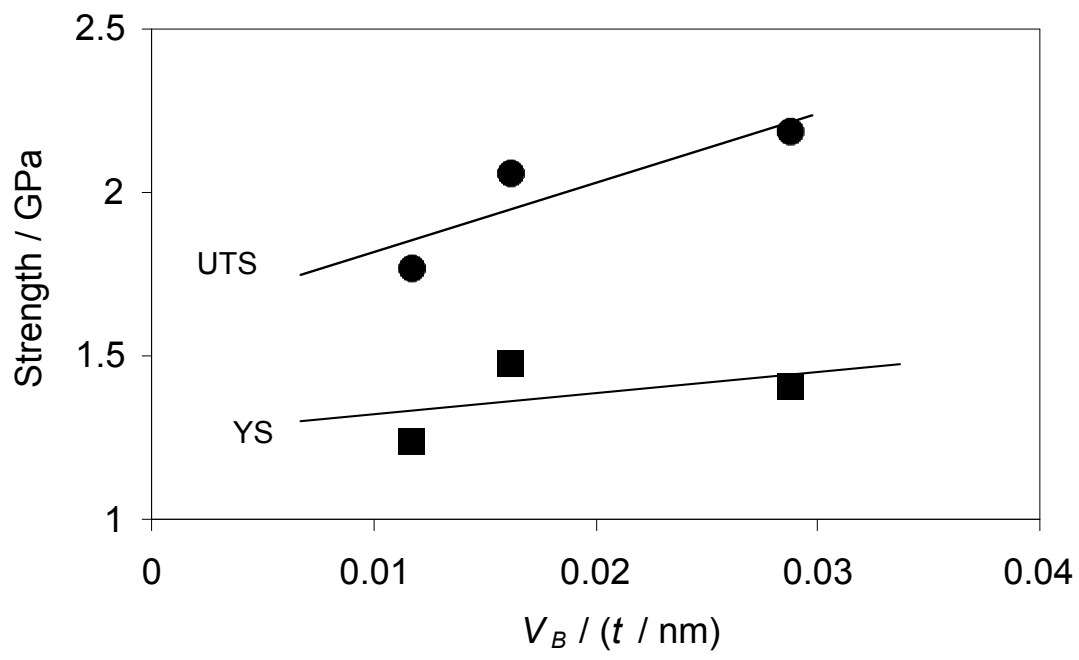

Fig. 4. Strength versus $V_{b} / t$.

There are other operative strengthening mechanisms which are expected to contribute; in particular, the excess carbon concentration in the ferrite and the dislocation density, Fig. 1. The excess carbon is a consequence of the displacive mode of transformation and its presence has been independently verified using X-ray analysis and atom-probe measurements [15,16]. A strong correlation exists between the carbon content and the calculated dislocation density [15], Fig. 5, which suggests that the carbon may be trapped at dislocations in the bainitic ferrite as originally suggested for martensite by Kalish and Cohen [17]. Therefore, there may be no independent contribution of carbon in solid solution, but rather, through its effect on the mobility of dislocations.

Theory indicates that the strength increment due to dislocations is given by $\Delta \sigma \cong 7.3410^{-6}(\rho)^{0.5}$ [18], where $\rho$ is given in $\mathrm{m}^{-2}$ and $\Delta \sigma$ in MPa. Fig. 6 summarizes the contributions of the main different strengthening mechanisms after being corrected by their corresponding ferrite volume fractions. As expected, at the lowest transformation temperature, with $87 \%$ of bainitic ferrite present in the microstructure, the contribution from the fine plate size is very large, $1.6 \mathrm{GPa}$; that from dislocations is about $500 \mathrm{MPa}$. At higher transformation temperatures, the ferrite fraction decreases while its thickness increases, leading to smaller contributions from both of these strengthening mechanisms. The microstructural contributions for the $300^{\circ} \mathrm{C}$ transformed samples are only about 600 and $300 \mathrm{MPa}$ for plate thickness and dislocation density strengthening respectively.

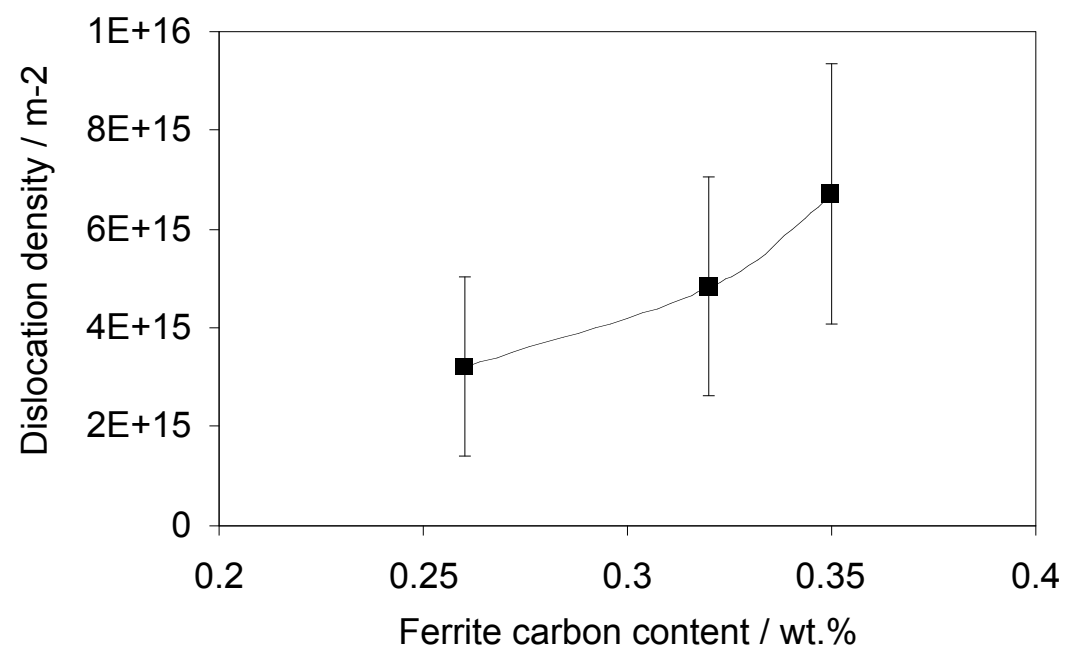

Fig. 5. Plot showing the relation between ferrite dislocation density and its carbon content following transformation. 


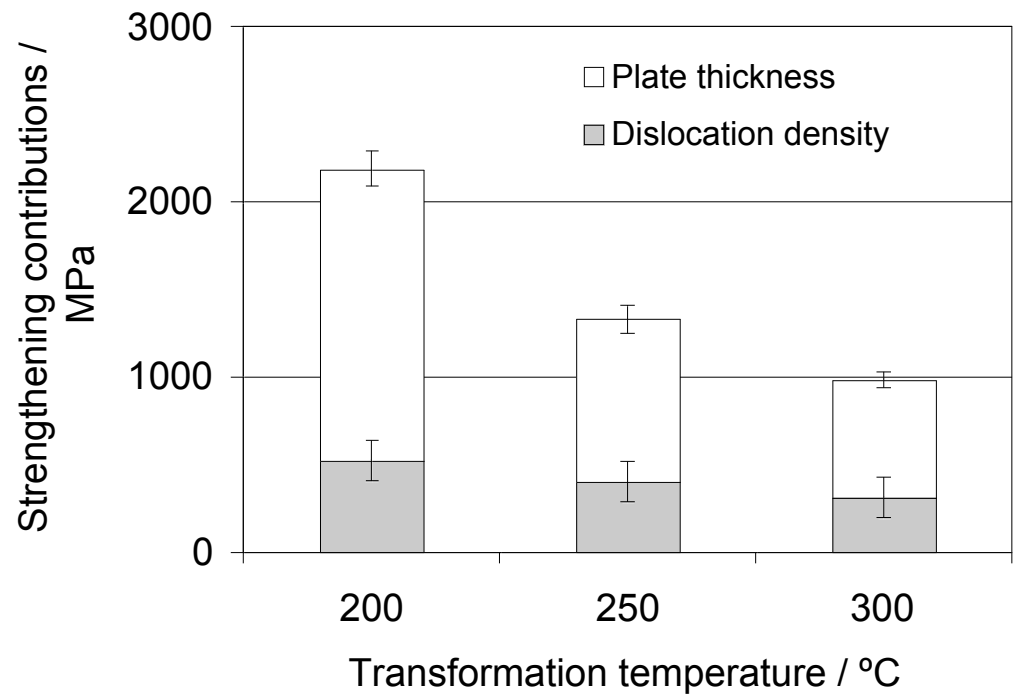

Fig. 6. Strengthening contributions versus transformation temperature.

On the other hand, toughness and ductility seem to be controlled by the amount of retained austenite present in the microstructure, Fig. 1 and Fig. 3.. The microstructure obtained at $300^{\circ} \mathrm{C}$ exhibits the best results with $25 \%$ of retained austenite present after the completion of reaction, lower levels are achieved with the stronger microstructure obtained after transformation at $200^{\circ} \mathrm{C}$.

Fig. 7 compares the properties of the present steel against published data [19]; it is evident that the low temperature bainitic steel has an exceptional combination of mechanical properties.

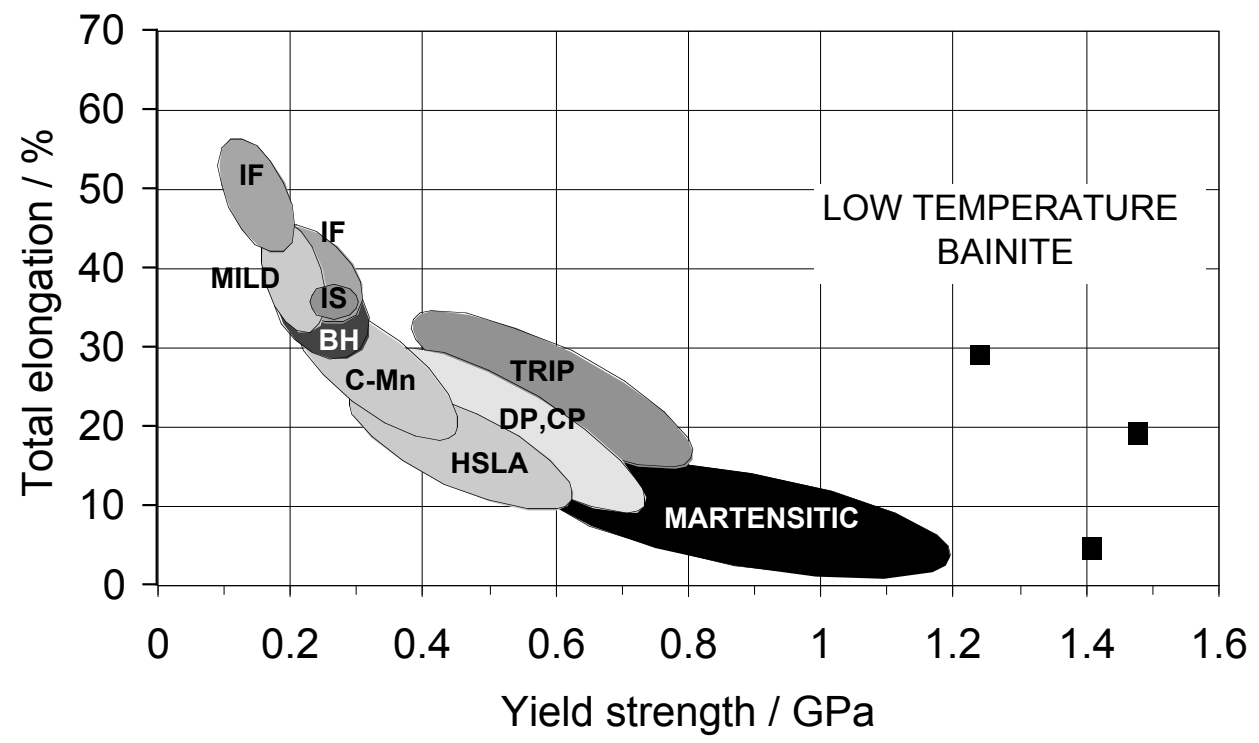

Fig. 7. Comparison of strength versus total elongation of conventional steels and low-temperature bainitic steels. IF-interstitial free, CMn-carbon manganese, BH- bake hardenable, IS-isotropic, DP- dual phase,

CP-complex phase [19].

\section{Conclusions}

A mixed microstructure of retained austenite and extremely fine bainitic ferrite plates, developed from austenite by isothermal transformation al low temperatures $\left(200-300^{\circ} \mathrm{C}\right)$, has been tested in order to characterise its mechanical properties. The strength/ductility combinations reported have 
not been previously achieved in bainitic steels. It was found that the extraordinary slender plates of bainitic ferrite in conjunction with high dislocation density in ferrite, are the main strengthening mechanisms operating.

\section{Acknowledgements}

The authors acknowledge financial support from the Spanish Comisión Interministerial de Ciencia y Tecnología (CICYT) (project-MAT 2001-1617). F.G. Caballero and C. Garcia-Mateo would like to thank Spanish Ministerio de Ciencia y Tecnología for the financial support in the form of a Ramón y Cajal contract (Programa RyC 2002 and 2004 respectively). Some of this work was carried out under the auspices of an EPSRC/MOD sponsored project on bainitic steels at the University of Cambridge; we are extremely grateful for this support over a period of three years.

\section{References}

[1] H.K.D.H. Bhadeshia. Bainite in Steels ( $2^{\text {nd }}$ Edition, Institute of Materials, London 2001).

[2] C. Garcia-Mateo, F.G. Caballero and H.K.D.H. Bhadeshia, J. Phys. IV, 112 (2003), p.p. 285288.

[3] C. Garcia-Mateo, F.G. Caballero and H.K.D.H. Bhadeshia, ISIJ Int. 43 (2003), p.p. 1238-1243.

[4] C. Garcia-Mateo, F.G. Caballero and H.K.D.H. Bhadeshia, ISIJ Int. 43 (2003), p.p. 1821-1825.

[5] M.J.J. Dickson. Journal of applied Crystallography 2 (1969) p.p. 176-180.

[6] H.K.D.H. Bhadeshia, S.A. David, J.M. Vitek and R.W. Reed, Mater. Sci. Technol., 7 (1991), p.p. 686-698.

[7] G.K. Williamson and W.H. Hall, Acta Metall., 1 (1953), p.p. 22-31.

[8] G.K. Williamson and R.E. Smallman, Philos. Mag., (1956), p.34

[9] M.K. Fondekar, A.M. Rao and A.K. Mallik, Metall. Trans., 1 (1970), p.p. 885-890.

[10] S.B. Singh and H.K.D.H Bhadeshia, Mater Sci. Eng. A, 245 (1998), p.p. $72-79$.

[11] E.E: Underwood: Quantitative microscopy. (Ed. R.T. Dehoff and F.N. Rhines, McGrawHill, New York 1968).

[12] H. K. D. H. Bhadeshia: Mathematical Modelling of Weld Phenomena III (Institute of Materials, London 1997).

[13] G. Langford, and M. Cohen : Trans. ASM 62 (1969), p. 623

[14] G. Langford, and M. Cohen : Metallurgical Transactions 1 (1970), p. 1478

[15] C. Garcia-Mateo, M. Peet, F.G. Caballero and H.K.D.H. Bhadeshia, Mater. Sci. Technol., 20 (2004), p.p. 814-818.

[16] M. Peet, S.S. Babu, M.K. Miller and H.K.D.H. Bhadeshia, Scripta Mater. 50, (2004) p.p. 1277-1281.

[17] D. Kalish and M. Cohen, Mater. Sci. Eng., 6 (1970), p.p. 156-166

[18] R.W.K. Honeycombe and H.K.D.H. Bhadeshia. Steels. Microstructure and Properties $\left(2^{\text {nd }}\right.$ Edition, Edward Arnold, London 1995).

[19] http://www.worldautosteel.org/ulsab-avc/imagelib/pages/087.htm 